\title{
On the Advantages and Feasibility of Weather Index-Based Crop Insurance Schemes in Bolivia
}

\author{
(AAM of a paper published online on 06 December 2019 in Emerging \\ Markets Finance \& Trade. DOI: 10.1080/1540496X.2019.1677226)
}

Ricardo Nogales C.

Center for Research in Economics and Management, Universidad Privada Boliviana

Campus "Santa Rosa”, Av. Capitán V. Ustáriz Km. 6.5

+59144268287

rnogales@upb.edu

Pamela Córdova O.

Center for Research in Economics and Management,

Universidad Privada Boliviana

Campus "Santa Rosa”, Av. Capitán V. Ustáriz Km. 6.5

$+59144268287$

pcordova@upb.edu

\begin{abstract}
Weather index-based insurance schemes are gaining attention as instruments for agricultural risk management. A key difference between these insurance schemes and more traditional ones is that the former can cope more effectively with adverse selection and moral hazard issues, which may yield less expensive insurance contracts. Thus public institutions in Bolivia currently promote indexbased schemes in the quest of increasing food safety, reducing vulnerabilities in agriculture-dependent poor rural regions and improving poor producers' livelihoods. This constitutes an important innovation in the country in the sense that the construction of indexbased schemes follows quite different patterns compared to traditional
\end{abstract}


crop insurance mechanisms. The development of index-based schemes needs to be assessed in the specific context of the country's economic environment and the configuration of insurance markets. Taking these aspects into account, this chapter presents the technical requirements and methodological steps for the construction of indexbased schemes and discusses sources and availability of suitable information in Bolivia. Following the proposed methodological steps, insurance schemes for wheat and potato are developed for Anzaldo, one of Bolivia's poorest agricultural-dependent rural municipalities. The proposed insurance schemes are compared to the country's current public crop-insurance program, Pachamama, which builds on traditional schemes, proving that index-based schemes that offer variable reimbursing according to climate-induced crop damage allows the manage similar climate risks with potentially lower policy prices. Thus index-based insurance are presented as suitable complements for current public efforts towards a sustainable inclusion of poor rural producers into the dynamics of the insurance market in Bolivia.

\section{Introduction}

Climate change has increased risks and challenges for sustainable agricultural activities throughout the world. The management of this risk is especially relevant when there is a vast population that relies on agricultural activities as a main source of income, which is the case 
of Bolivia 1 . If climate risks are not properly managed, not only the socioeconomic stability of producers is compromised but they would be increasingly inclined to abandon this economic activity aiming at more stable sources of income and wellbeing, thus implying an important drawback for food safety and food sovereignty [Mertz, Halsnaes and Olesen, 2009]. Accordingly, 75\% of the governments in Latin America and the Caribbean consider management of climate risks and development of crop insurance as a 'high' or 'very high' priorities in their public policy agendas [Hatch et al., 2012; Barnett and Mahul, 2007]. One plausible way to approach this issue is the development of different crop insurance schemes, which international interest among politicians and academics has been steadily increasing.

Active participation of governments and international agencies in the development of these financial instruments has been a common trait throughout the world [Hazell, Pomareda and Valdés, 1992; Skees, 2008]. Indeed, it has proven particularly difficult for rural insurance markets to develop naturally, relying only on market forces, mainly due to the fact that rural areas present considerable systematic risks that are difficult (sometimes impossible) to manage by private financial institutions. As a result, according to Hatch el al., 2012, only $3.5 \%$ of the world's agricultural insurance market is concentrated in Latin America and the Caribbean.

The small scale of insurance activity in rural areas has origin in specific characteristics of the demand and the supply sides of insurance markets [Collier, Skees and Barnett, 2009]. As in many developing countries, demand in Bolivia is limited by low purchasing power of most producers in rural areas and the absence of insurance culture and other financial practices, among others. This reality interacts with scarcity of supply of insurance services, which one can think is due to the concentration of the biggest financial institutions on the development of instruments and mechanisms that are suitable

\footnotetext{
${ }^{1}$ According to the World Bank, by $2009,32 \%$ of the occupied working force in the country is in the agricultural sector.
} 
for risk management in urban areas only. Even if this practice has produced healthy results for insurance institutions in Bolivia ${ }^{2}$, one may argue that it has also resulted in limited innovation dynamics and tacit neglect of understanding risks in rural areas, particularly those associated to primary agricultural activities, and the characteristics and drivers of demand for insurance services of this market segment.

This chapter will focus on current limitations of the supply side of the rural insurance market in Bolivia and present how specific crop insurance schemes were developed, making a case for them as one suitable way to give an impulse to risk management in rural areas, alongside positive economic and social spill-overs. Discussion is built around the ordered general steps that led to the construction of the first climate index-based crop insurance schemes in the Bolivia that are considered for public policy purposes. This kind of insurance scheme has been applied with success in the continent, but they remain an uncommon practice in the region in general and in Bolivia in particular, thus the availability of the required information for the construction of these schemes, as well as its sources and treatment will be discussed thoroughly. The feasibility of this type of crop insurance in the country is proved, presenting details of pilot schemes for wheat and potato crops in Anzaldo, a rural Municipality of Cochabamba.

This chapter is structured as follows: Section 2 presents and analyzes the most important characteristics of the Bolivian insurance market and provides relevant elements of comparison with international experience. Section 3 describes ordered technical and theoretical aspects of the methodological steps that have led to the creation of climate index-based insurance schemes in Bolivia. Section 4 describes and analyses the elements of these schemes that are deducted from information provided in the previous section. The crux of the chapter, in terms of novel empirical evidence on climate index-

${ }^{2}$ For instance, according to Mapfre Foundation, the net financial result of the country's insurance market increased in $15.7 \%$ between 2011 and 2012 . 
based insurance for the Bolivian case, lies in Sections 5 and 6, which present the application of the previous methodological steps to the specific case of the country and discuss details of the insurance policies that result from this application. Finally, the key ideas of the chapter are summarized as Concluding Remarks.

\section{The Context for Agricultural Insurance in Bolivia and Brief Review of International Experience}

Political and academic efforts have mainly tended to focus on the development of two large groups of insurance schemes throughout the world [Barnett, 2014; Dinku et al., 2009; Hatch et al., 2012]. The first are traditional crop insurance schemes, which are founded on 'in situ' assessment of crop damage and their causes, and the second are indexbased crop insurance schemes, which rely on an indirect monitoring of crop damage through proxy variables.

Traditional crop insurance schemes have proven effective for the management of specific and multiple risks, for instance, of wheat and corn in Mexico, soy beans, wheat and corn in Brazil and different cereals in Argentina [Hatch et al. 2012]. However, since this type of insurance relies on damage assessment by experts, they can result in high insurance policy prices that may hinder the scaling-up of this financial practice in developing countries [Barnett and Mahul, 2007; Skees, 2008].

In contrasting fashion, index-based crop insurance schemes are alternative mechanisms that normally result in lower management costs, as they build upon the track of one or more proxy variables that are highly correlated to crop development and are easily available. These variables form an 'index' for the crop yield and when they are related to climate conditions, one refers to climate index-based insurance. These schemes remain a financial practice that has still great potential for scaling up and becoming a regular/common 
instrument for crop insurance [Collier, Skees and Barnett, 2009]. One plausible explanation for this is the fact that the construction of this type of insurance schemes implies important sunk costs that arise, for instance, from financial and technical research, gain of know-how for financial institutions and gathering of adequate information and infrastructure for climate monitoring [Dinku et al., 2009; Giné, 2009; Hatch et al., 2012; Osgood et al., 2007]. Furthermore, since it is not a regular financial practice, clients may be reluctant to assure their main source of income through an instrument they are not familiar with. The demand shift from traditional insurance schemes to this novel type of schemes may not occur smoothly due to important asymmetry of information. Despite these challenges, there are remarkable advances in terms of development of climate index-based insurance of corn in Ethiopia [Dercon, 2004; Dinku et al., 2009] and Malawi [Hellmuth et al., 2007;], potato in India [Giné, 2009] wheat and corn in Mexico [Osgood et al., 2007].

As we mentioned in introductory paragraphs, successful international experiences have the common characteristic of having been fostered by private-public alliances. The role of public agencies and international organizations in the region has gone from price subsidies to financing research and adapting regulatory frameworks timely and accurately, some examples being Mexico, India and Malawi [Hellmuth et al., 2007].

The Bolivian crop insurance market is currently at an early stage of development. Some of the most notorious efforts that have ignited supply of this type of insurance started around a decade ago, coming from low scale enterprises by Non-Governmental Organizations, such as Profin Foundation ${ }^{3}$, Prosuko ${ }^{4}$ and Unapa ${ }^{5}$ and international organizations and cooperation. However, the participation of private insurers has always been more limited.

\footnotetext{
${ }^{3}$ Program for Support to the Financial Sector.

${ }^{4}$ Program of Suka Kollus.

${ }^{5}$ Association of Producers from Bolivia's Highlands.
} 
In recent years, advances in the country in terms of crop insurance have been complemented by an important set of public initiatives, ignited by the institution of the design, implementation and management of these types of insurance schemes as a constitutional mandate since 2009. One of the first practical efforts towards the fulfillment of this mandate is the establishment of the Universal Agricultural Insurance Pachamama (UAIP) ${ }^{6}$. In complementary fashion, the National Institute for Agricultural Insurance was created in 2011 as an office within the Ministry of Rural Development and Land with the sole purpose of regulating, implementing and developing UAIP.

Initially, this insurance focused on protecting the crops in the municipalities with the highest levels of extreme poverty in the country [Hatch et al., 2011]. UAIP prioritized protection of crops of wheat, corn, oat, quinoa, barley, green beans and potato against flood, drought, hail and frost. Today, the insurance covers around 186000 hectares corresponding to 200000 families of producers in 115 municipalities (34\%) of the country. The amount of reimbursement is currently fixed at $144 \mathrm{USD} / \mathrm{ha}$ holding no relation to production costs or expected revenues. The insured producers are not required to make any payments for the policy; it is fully subsidized by the State. In essence, the ignition of large-scale crop insurance in Bolivia was led by a public policy that had little resemblance to a risk management mechanism; it was more similar to a conditional public transfer as a means of assistance to poor producers.

The increasing social and economic importance of UAIP may draw an important challenge for the country: assessing the feasibility and adequacy of shifting the current configuration of the insurance from a fully subsidized service towards a (at least partially) market-driven scheme where producers absorb part of the risk. Indeed, the current fully subsidized configuration might threaten future fiscal stability

\footnotetext{
${ }^{6}$ A word in Bolivian indigenous language Quechua that means Mother Earth, which is considered a divine entity in this native culture.
} 
and long-term development of agricultural insurance. Furthermore, from a financial perspective, charging a part of the insurance policy price to the producers would reduce moral hazard and adverse selection issues, helping set solid grounds for the ignition and the sustainable expansion of an actual crop insurance market in the country. The development of climate index-based insurance schemes can be part of the strategy that has to be set in order to successfully face this challenge. The lower prices that result from this type of insurance schemes, relative to more traditional ones, may allow a more smooth and dynamic expansion of the supply side of the market while performing adequate risk management.

Based on this line of reasoning, the development of climate indexbased schemes in Bolivia has been ignited in 2013 through the creation of pilot insurance schemes for potato and wheat in the municipality of Anzaldo, which ordered steps of construction, are presented and discussed in detail in the following section.

\section{Construction of Climate-Based Crop Insurance Schemes in Bolivia: Ordered Methodological Steps}

Inspired in Collier et al., 2009, Deng et al., 2008, Dinku et al., 2009, Hatch et al., 2012, Osgood et al., 2007 and Varangis, Skees \& Barnett, 2002 , the construction of climate index-based insurance schemes in Bolivia has followed three general steps: i) indexing of climate risks in a specific area for the crop of interests, ii) measurement of climate risks and iii) design of the insurance policy schemes. Each of these steps combine climate, financial and agrobiologic information. Important issues about technical characteristics of these steps are highlighted here with twofold purpose. The first is to set solid grounds for presentation of their application in the Bolivian case and the second is to contribute to the related literature with some ordered 
arguments for ways of constructing climate index-based insurance schemes in the context of developing countries.

\section{Indexing Climate Risks}

Climate risks can be indexed when it is possible to identify and quantify one or more climate variables that are highly correlated to the crop yield that one wants to insure. In this context, the correlation between the climate index and the crop yield can be associated to a causal relation from the first to the latter. However, a consensually adequate degree of correlation between these two variables is impossible to establish. Different types of indices have proven useful in different contexts for different crops. For instance, rainfall has been used for indexing wheat and corn yields in Malawi and Mexico [Osgood et al., 2007], whereas rainfall, temperature and humidity were combined in a climate index for potato crop insurance in India [Giné, 2009].

Among the positive aspects of indexing climate risks, from a financial institution's perspective, highlight the mitigation of asymmetry of information issues with respect to more traditional insurance schemes. Indexing allows a more adequate management of adverse selection through the constitution of insurance portfolios that combine areas and crops of interest and not specific individual clients. This is tightly linked to the benefits of indexing in terms of reduction of moral hazard, because the index cannot be controlled by any of the insured clients. These benefits result in cost reduction and the possibility of lower insurance policy prices in a competitive context, generating financial benefits for the clients.

However, a potentially negative aspect counterbalances these important benefits of indexing climate risks: one cannot suppress possible dissociations between the climate index and the actual crop yield, though they can be minimized. This is called the basis risk and 
it is intrinsic to any kind of index-based insurance; as is the case for every proxy variable, the index allows only a partial reproduction of the actual crop yield. This risk has to be taken into account from the very conception of the insurance scheme, because if it is not managed adequately, it can progressively discredit this financial practice from the clients' perspective and endanger the sustainable development of crop insurance markets in the country. Furthermore, the basis risk makes it clear that indexing climate risks requires focusing on specific crops in specific areas, with impossibility of extrapolation.

Once the essential characteristics of climate-index based insurance schemes have been presented, it is convenient to describe the technical aspects that were taken into account in the Bolivian case for indexing climate risks. It is important to analyse thoroughly the relation between the yield of a specific crop and its surrounding climate conditions [Hatch et al., 2012]. For this, three elements need to be taken into account: i) the existence of high frequency historical record of climate conditions in the area of interest, ii) detailed knowledge about the phenology of the crop that one ones to ensure and iii) availability of yield time series of this crop in a specific area of interest. It is important to discuss plausible sources and treatment of these three elements in order to show how they are combined to result in climate indices.

\section{Times Series of Climate Conditions}

The existence of adequate and reliable climate data is an important issue, especially in developing countries, because limited infrastructure often hinders sustainable tracking of climate conditions [Collier et al., 2009; Deng et al., 2008]. Important public and private efforts are being undertaken in Bolivia in order to establish a wide centralized network of weather stations across the country. At this stage, it is important to mention that weather information coming from private stations that are not recognized by public agencies 
should not be considered as suitable source for indexing climate risks. This information might imply a drawback for transparency and reliability of the index, reinforcing asymmetry of information problems in these insurance schemes. In the Bolivian case, the National Service of Meteorology and Hydrology provides official weather information.

Even with great efforts for complete and adequate climate data, these records always present missing values, commonly due to maintenance periods of the stations. Indexing climate risks is an impossible task in presence of missing values; not knowing the climate conditions in a specific point in time implies not knowing the value of the climate index and hence the climate risks. There are several simple, yet suitable techniques for filling missing values in these series [Schneider, 2001], that build on space extrapolation and require the identification of other adequately proximate weather stations that operate at a similar height above sea level [Collier et al., 2009; Deng et al. 2008; Varangis et al., 2002]; these are called 'reference stations'.

In order to present an ordered discussion around benefits and drawbacks of some of the most commonly used techniques, let us define $x_{i n t, t}$ and $x_{r e f_{-} i, t}$ representing the values of a specific climate variable, say temperature, humidity or rainfall, registered in period $\mathrm{t}=1 \ldots \mathrm{T}$, respectively, by the station of interest and the $\mathrm{i}$-th reference station, with $\mathrm{i}=1 \ldots \mathrm{n}$. Should $x_{\text {int }, t}$ be a missing value, estimates can be found using:

- A Simple Average of observed contemporary records of the reference stations: $\hat{x}_{i n t, t}^{S A}=\frac{1}{m_{t}} \sum_{i=1}^{m_{t}} x_{\text {ref } \_i, t}$ where $m_{t}$ is the number of reference stations that have registered values for the climate variable in period t. This is by far, the most intuitive and simple technique, but when applied one has to bear in mind that implicitly, one is accepting the a priori hypothesis that the information coming 
from each reference station has to be given the same weight (i.e. the same importance).

- A Weighted Linear Combination of the observed contemporary records of the reference station: $\hat{x}_{i n t, t}^{W L C}=\sum_{i=1}^{m_{t}} \frac{r_{i}}{\sum_{j=1}^{m} r_{j}} x_{\text {ref }} i, t$ where $m_{t}$ is the same as above and $r_{i}$ is the Pearson correlation coefficient between the station of interest and the $i$-th reference station. This means that the information of each reference station is given greater importance if it holds a strong historical statistical relation with that of the station of interest. Thus this technique overcomes some limitations in a simple average.

- Multiple Regression postulating an imperfect causal relation from the information of the reference stations to that of the station of interest: $x_{\text {int }, t}=\beta_{0}+\sum_{i=1}^{n} \beta_{i} x_{\text {ref_it }}+\varepsilon_{t} \forall t=1 \ldots T$ where $\beta_{0}$ is a constant term representing the mean value over the elements of vector $\boldsymbol{x}_{\boldsymbol{i n t}}$ sized (Tx1) from which the information of the reference station can be used to fill the missing values; each $\beta_{i}$ represents the impact of a marginal change in $x_{\text {ref } f_{-}, t}$ on $x_{i n t, t}$ holding constant the information of the other reference stations and $\varepsilon_{t}$ are stochastic residuals with zero mean and potentially time-dependent variance. Even if the causal relation might not hold from a theoretical point of view in this context, this technique sheds more realistic light on plausible values for missing data because it introduces a stochastic term representing the error of using information reference stations as predictor of the missing values. This error can be minimized using Least Squares methods, thus missing values can be estimated as $\hat{x}_{i n t, t}^{L S}=\hat{\beta}_{0}+\sum_{i=1}^{n} \hat{\beta}_{i} x_{\text {ref_i,t }}$. In order to avoid statistical fallacies, since we are treating time varying data, it is useful to prove the existence of at least one cointegrating vector for these variables, so that the equation used for filling missing data can be interpreted as a cointegrating relation [Ferreira, 2003].

Each of these three usual techniques is a correct way for estimating missing values. One can assess the appropriateness of each technique 
under the light of their Mean Squared Error (MSE) of prediction:

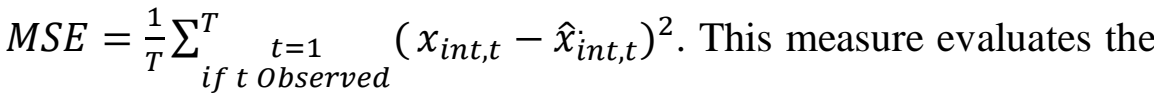
deviation (over or under targeting) of the predicted values from the observed values of the series. For a perfect prediction technique $\mathrm{MSE}=0$, thus low values of MSE are best.

\section{Crop Phenology}

Indexing climate risks requires an assessment of the damage than can cause adverse climate conditions to the adequate biological development of a crop and subsequently to the yield. This relation is called the crop phenology; along the vital cycle of a crop, visible physical changes occur, such as germination, bud-burst, leaf expansion, flowering and fruiting [Fenner, 1996]. These physical changes define stages in the crop phenology and they are heavily influenced by soil characteristics, agricultural practices and the species of the crop, which configure its genetic traits.

The relation between climate conditions and the crop yield vary from one stage of phenology to another. For instance, rainwater requirements are different if the crop is at an early stage of development or if it is ready for harvesting. Adequate indexing of climate risks consists on identifying the most important stages of the crop phenology with respect to the climate variable that one wants to insure. For instance, in Hellmuth et al. (2009) it is stressed that an adequate index for coffee crops in Honduras and Nicaragua consist of cumulated rainwater in three different stages of phenology when one wants to create an index for protection against drought and in another two different stages if one aims at protection against flood. Furthermore, they have found different weights for deficit of rainfall in each of these stages.

The crop phenology is one the main sources of basis risk and marks one the main challenges for the development of climate index-based 
insurance. In effect, it is clear that crop phenology is very specific and cannot be extrapolated to other regions or even other species of a crop. Specific studies have to be carried on in order to identify and understand the phenology of each crop that one ones to insure; otherwise, the basis risk would be amplified. This kind of information is scarce in Bolivia; however, the Ministry of Rural Development and Land carries on research on this subject, at a regular basis, building on information from Food and Agriculture Organization (FAO).

\section{Crop Yield Time Series}

In order to identify the adequate climate risk for a crop, one needs to assess and quantify the historical relation between the climate conditions and the crop yield. In developing countries, time series for crop yield are very short, should they come to exist [Osgood et al., 2007]. This information is often simulated through agro-biological systems yielding synthetic crop yields. It is beyond the scope of this chapter to present a thorough discussion about these systems (for further details, refer to Osgood et al., 2007). We cannot omit, though, to present the main characteristics of the most commonly used ones.

One of the first and most simple agro-biological systems is the Water Requirement Satisfaction Index (WRSI) developed by FAO in 1996, which served as solid foundation for the construction of climate index based insurance for wheat against drought in Tanzania, Malawi and Kenya [Osgood et al., 2007]. The WRSI is considered a simple system for it allows for constructing synthetic yields building on the combination of the phenologic cycle of the crop and the available water for its development.

A more sophisticated version of WRSI, which has also been proposed by FAO in 2009, is AquaCrop [Raes et al. 2009]. This system has also set solid grounds for the development of climate index-based insurances for wheat, for example, in Africa and Central America [Dinku et al., 2009, Osgood et al., 2007]. In contrasting 
fashion to WRSI, AquaCrop allows for constructing synthetic yields controlling for determinants other than disposable water, thus providing a more robust and fine relation between climate conditions and crop yield. These determinants include highest and lowest temperature levels to which the crop has been exposed and physical as well as chemical characteristics of the soil it grew on.

A third and more complex system is the Decision Support System for Agrotechnology Transfer (DSSAT) developed by an international network of public and academic institutions including University of Florida and Washington State University, among others, in 1983 [Hoogenboom et al., 2003]. DSSAT allows for a greater number of control variables for the relation between climate conditions and crop yields, which include solar radiation, genetic information of the crop and atmospheric humidity [Jones et al., 2003]. Nevertheless, the sophistication and precision of DSSAT is counterweighted by the availability of the information it requires for the construction of synthetic crop yields, which may be prohibitive for most weather stations, especially in developing countries.

The three agro-biological systems that have been described are a plausible solution for the absence of actual crop yield time series, and that they are a much suitable alternative to relying on producers' memory as has been the case in Nicaragua and Honduras for coffee crops [Hellmuth et al., 2009].

The partially controlled experiments performed by these systems allow for a better understanding of the relation between climate conditions and crop yields, which is a crucial issue for successful climate risk indexing. Is it important to stress though, that whenever adequate information exists, one should always seek for validation of the synthetic yields resulting from these systems. The source of validation is a delicate issue that is discussed in Deng et al., 2008, where strong arguments are presented in favour of secondary information by experienced NGO's and producers' associations. 


\section{Crop Indexing Model: a Proposal}

Once all the adequate information regarding climate conditions and crop yields is disposable, crop indexing can be conducted in a relatively straightforward manner. The Bolivian pilot insurance schemes have been constructed to protect crop yields against drought, which is why the remainder of the chapter focuses on the creation of a climate indexed based on rainfall net of seepage, allowing to gauge the disposable rainwater for the development of the crop. In order to capture different effects of disposable water in different phenological states, the development cycle of the crop was divided in periods of ten days called decadals [Osgood et al., 2007; Pabón and Dorado, 2008].

Let us define two variables of particular interest: $y_{t}$ denoting the yield in period $t$ (actual or synthetic) for the crop of interest, and $C D R_{t, d}$ denoting the cumulated disposable rainwater during a span of time $d$ in period $t$.

The relation between these variables in every period $t$ can be captured by the following econometric equation:

$$
y_{t}=E\left[y_{t} \mid C D R_{t}, \boldsymbol{Z}_{\boldsymbol{t}}\right]+\varepsilon_{t}=\beta_{0}+\sum_{d=1}^{D} C D R_{t, d} \cdot \beta_{d}+\boldsymbol{Z}_{\boldsymbol{t}} \boldsymbol{\gamma}+\varepsilon_{t}
$$

that decomposes the observed crop yield into an expected, thus predictable value, $E\left[y_{t} \mid C D R_{t}, Z_{t}\right]$ and a random stochastic term that captures all the other determinants of the crop yield that cannot be predicted by our model, $\varepsilon_{t}$; say this random term has zero expectation and finite variance.

In the above equation, D represents the end of the crop development cycle, i.e. the period of time between planting and harvesting, thus $\beta_{d}$ gauges the impact of the cumulated disposable rainwater in span of time $d$ over the crop yield, $d=1 \ldots D$. Vector $\boldsymbol{Z}_{\boldsymbol{t}}$ includes other determinants of the crop yield such as a trend or specific 
characteristics of each time period, depicting, for instance, unusual weather phenomena (e.g. el Niño). The vector of parameters $\gamma$ captures the impact of these other determinants and their inclusion in the proposed model is important as it allows for a better estimation of each $\beta_{d}$, which are the parameters of interest in the equation. Parameter $\beta_{0}$ captures the level from which the crop yield is affected by all variables included in the equation. In order for the econometric equation to be correctly specified, all the time series variables need to pass tests for covariance stationarity or cointegration [Collier et al., 2009].

This framework allows identifying the spans of time in the development of the crop that can be considered for climate indexing on the grounds of a simple statistical significance test of the structural parameters, say a student test:

Null hypothesis: $\quad \beta_{d}=0$ span of time $d$ should be considered for $\rightarrow \quad$ climate indexing

Alternative $\quad \beta_{d} \neq 0$ span of time $d$ should not be hypothesis: $\quad \rightarrow \quad$ considered for climate indexing

Furthermore, complementary statistical tests for identifying the highest valued structural parameter, say a Wald test can allow identifying which of the relevant spans of time for climate indexing should be prioritized:

Null hypothesis: $\quad\left|\beta_{d}\right|>\left|\beta_{g}\right|$ span of time $\mathrm{d}$ should be prioritized $\rightarrow \quad$ over span of time $\mathrm{g}$

Alternative $\quad\left|\beta_{d}\right| \leq\left|\beta_{g}\right|$ span of time $\mathrm{d}$ should not be hypothesis: $\quad \rightarrow \quad$ prioritized over span of time $g$ 


\section{Climate Risk Measurement}

The statistical distribution that underlies the identified climate index defines the kind of climate risk the crop is exposed to. By construction, the climate index model that we proposed creates a correspondence between the expected crop yield and the value taken by the climate index. In this context, understanding the statistical behaviour of the climate index becomes a necessary and sufficient condition for understanding the statistical behaviour of the crop yield of interest. Indeed, the probability of a specific value of the crop yield can be easily deduced from the probability of the climate index to take a certain value.

Understanding the statistical behaviour of the climate index requires the identification of an empirical or a mathematical representation of its density function or its respective cumulative distribution function, which can be achieved using either parametric or non-parametric techniques [Osgood et al., 2007; Collier et al., 2009]. Two widely used non-parametric techniques that are suitable for this task are the Cumulated Frequency Functions (CFF) and the estimation of core or kernel of the underlying empirical distribution of the climate index.

The CFF method consists in the extrapolation of observed values of the index to a continuum of values, linking frequencies of consecutive observed values. Formally, let us define the set of ordered observed values $\mathrm{X}_{1} \ldots \mathrm{X}_{\mathrm{n}}$ associated to the set of cumulated frequencies $\mathrm{F}_{1} \ldots \mathrm{F}_{\mathrm{n}}$. The probability $\mathrm{p}\left\{\mathrm{X} \leq \mathrm{X}_{\mathrm{h}}\right\}$ for every $\mathrm{i} \leq \mathrm{h} \leq \mathrm{j}$ can be estimated by $\hat{p}\left\{X \leq X_{h}\right\}=F_{j}+\left[\frac{F_{j}-F_{i}}{X_{j}-X_{i}}\right]\left(X_{h}-X_{j}\right)$.

The estimation of the core or kernel of the climate index distribution allows for estimating a probability for a precise value of this variable, $\mathrm{p}\{\mathrm{X}=\mathrm{x}\} \forall \mathrm{x} \in \mathfrak{D}$ (the domain of the index), instead of a range, as is the case of the cumulated frequency functions. This probability is estimated as $\hat{\mathrm{p}}\{\mathrm{X}=\mathrm{x}\}=\frac{1}{\mathrm{n}} \sum_{\mathrm{i}=1}^{\mathrm{n}} \frac{1}{\mathrm{~b}} \mathrm{~K}\left(\frac{\mathrm{x}-\mathrm{X}_{\mathrm{i}}}{\mathrm{b}}\right)$ where $\mathrm{K}(\cdot)$ is 
the kernel function [Turlach, 1993]. The selection of a mathematical expression of $\mathrm{K}(\cdot)$ should be compatible with a minimization of the MSE.

The two techniques proposed thus far for risk measurement, provide suitable empirical estimations of the distribution function of the climate index but do not yield a mathematical (parametric) expression for the latter. This parametric expression can be found through a Kolmogorov-Smirnov test:

Null hypothesis: $\quad F_{o}(x)=p\{X \leq x\}$ is a correct parametric representation of the cumulative distribution function

Alternative $\quad F_{o}(x)=p\{X \leq x\}$ is not a correct parametric hypothesis: representation of the cumulative distribution function

This test needs to be performed repeatedly with different $a$ priori known distribution functions in order to find the most adequate. According to Weber (2006), some of the most commonly used functions for risk measurement that allow only for positive values of the climate index are the Lognormal and Weibull distributions. Should the test come to accept the null hypothesis more than once for different distribution functions, the most suitable one for the climate index would be the one that minimizes the MSE.

\section{Towards Insurance Policies: Defining Elements of Climate Index-Based Insurance Schemes}

After the climate risk has been correctly measured, the basic technical foundations for climate index-based insuring are set. From this technical core, some important elements of insurance policies can be deduced [Collier et al., 2009; Deng et al., 2008; Osgood et al., 2007], 
namely i) the insurance trigger, ii) the reimbursement rate and iii) the maximum reimbursement.

At this point, it is important to mention that these elements should be defined taking into account characteristics of both the demand and supply sides of the insurance market. It has been established that analysis of the demand side lies beyond the scope of this chapter; however, some important aspects for the definition of these elements can be drawn from the perspective of suppliers of insurance service. This allows building a bridge between the technical elements of the insurance policies that have been presented thus far and the actual configuration and design of policy contracts in the Bolivian case. A graphical representation of these elements is provided in Fig. 1.

The insurance trigger, which will be noted $X_{\text {Trigger }}$, is the value of the climate index that ignites considerable climate-induced damage to the crop yield according to the climate risk indexing that was performed. When there is an inverse relation between the climate index and the crop yield, which is the case of the insurance against drought indexed by the disposable rainwater that is being treated in this chapter, the reimbursement is null when the climate index takes values greater than the insurance trigger.

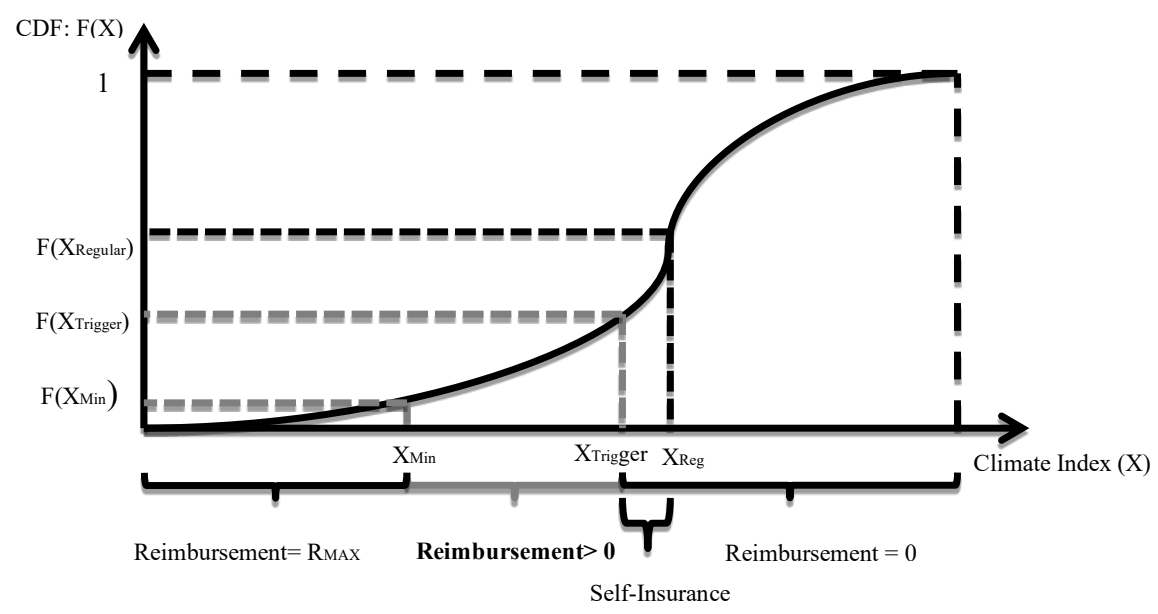


Fig. 1. Cumulative Distribution Function (CDF) of climate Index and Elements of the Insurance Scheme

From the insurer's perspective, $X_{\text {Trigger }}$ represents climate conditions that are considered worse than a 'usual' by the producers, which will be noted $X_{\text {Regular, }}$ and do not allow yields that can be considered 'regular'. The difference between $X_{\text {Trigger }}$ and $X_{\text {Regular }}$ that is accepted by the producers represents their willingness for selfinsurance [Osgood et al. 2007] and it might be an important quantitative proxy, for instance, for their risk aversion, willingness to pay for insurance and socioeconomic characteristics. The regular crop yields are linked to rational expectations from the producers, costs, climate history of the region of production or the mode in the yield time series. This reinforces the importance of characteristics of the demand side for the definition of the insurance trigger; the latter defines the climate conditions that imply a reimbursement for the producer and this, as in any insurance scheme, is ultimately their choice. However, should there be need for the definition of a maximum value of $X_{\text {Trigger }}, X_{\text {Regular }}$ is an adequate and objective option. In effect, Collier et al., 2009, Deng et al., 2008 and Varingis et al., 2002 argue against the supply of climate index based insurance guaranteeing an optimum yield for the produces, for it could entail high frequency of reimbursements and higher prices for the insurance service, reducing its potential for demand expansion in developing countries.

The maximum reimbursement $R_{\operatorname{Max}}$ is the amount that the producers would receive from the insurer when a minimum acceptable value for the climate index $X_{\text {Min }}$ has been attained, generating the most severe climate-induced damage to the crop as agreed by the insurer and the producer. The value taken by the climate index in this situation is also known as the exit trigger. Once again, the importance of the characteristics of the demand side is made evident, as well as the market negotiation process. However, it is 
important to notice that from the insurer's perspective, this situation does not to be a fortiori linked to null crop yield; it could be associated to a positive yield generating income for the producer that, given their costs, results in null financial utility.

The preceding discussion configures a range for the climate index for insurance against drought, $X^{*}=\left[X_{\text {Min }} ; X_{\text {Trigger }}\right]$, that holds a direct correspondence to the set of plausible reimbursements $R=$ $\left[0 ; R_{\operatorname{Max}}\right]$. Since the climate index and the crop yield are inversely related, the reimbursement rate that will be noted $R R$, is defined as the pace of increase of reimbursement with respect to the decrease of climate index: $R R \equiv \frac{d R}{d X^{*}}$. Thus this rate represents the monetary equivalent of each unit of 'harmful' climate index value. This linear correspondence between sets $X^{*}$ and $R$ has also been suggested in Osgood et al., 2007 for climate indexing of corn, for instance, in Malawi, Tanzania and Kenya.

Up to this point, attention has been drawn towards important details of the methodology for general construction of climate-index based insurance schemes. The application of this methodology to the Bolivian case is a complement to current public effort for protecting agricultural producers against adverse climate conditions. This is the reason why pilot insurance schemes were created for Anzaldo, a municipality that is included in UAIP's implementation program. In addition to being a part of this program, this municipality was chosen because it is covered by one the first official weather stations, thus allowing for large climate time series.

\section{Pilot Climate Index-Based Insurance Schemes for Wheat and Potato Crops in Anzaldo}

Anzaldo is located in the province Esteban Arce of the department of Cochabamba. It has a total extension of 28731.8 ha of which $21.2 \%$ is used for agricultural production, of which $82.8 \%$ of the area of 
agricultural use is dedicated to three crops: corn (34.6\%), wheat (34.3\%) and potato (13.9\%). Most of this production (79.4\%) is the result of rain fed cultivation only. Agricultural activities are particularly important for socioeconomic stability in this region, as it is the main source of income for $69.2 \%$ of its population (14 100 habitants). These facts are clear indicators of the appropriateness of the development of index-based insurance in the sense described in the introductory paragraphs of this chapter. For a comparison of insurance schemes for different crops, we focused on wheat and potato crops, capturing half of the agricultural activity in the municipality.

\section{Climate Information}

The core of the construction of the climate index-based insurance in Anzaldo is the existence of adequate climate information. There is an official weather station managed by the SENAMHI in the municipality that started functioning in 1943 and it has been gathering publicly available information on rainfall and temperature at daily basis since 1967 with relative regularity. The period of time 19672012 was used for the creation of the climate index, in order to efficiently use the available climate information.

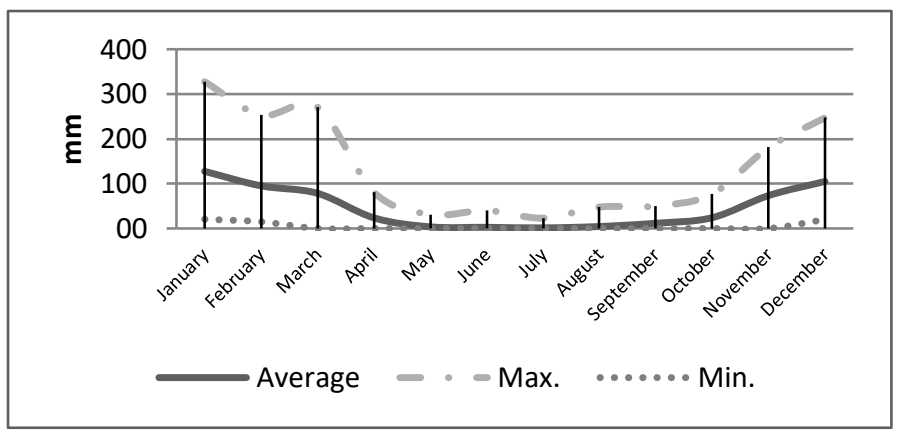


Fig. 2 Mean Cumulated Rainfall per Month in Anzaldo (19672012)

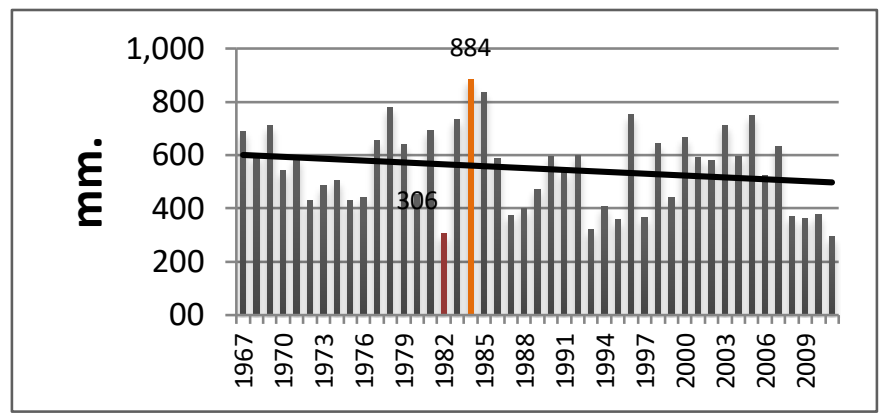

Fig. 3 Cumulated Rainfall per Year in Anzaldo (1967-2012) and Linear Trend

In this span of time, the mean annual cumulated rainfall is $550 \mathrm{~mm}$. As depicted in Fig. 2, the highest rainfall occurs in January, December and February, which correspond to summer in the southern countries. Given the climate conditions of this area, the agricultural cycle corresponds to the period of time between October (early spring) and March (early autumn) of the following year. As shown in Fig. 3, the cumulated rainfall in the agricultural cycle has a decreasing trend, at rate of $3 \mathrm{~mm}$./year in the period 1967-2012. Furthermore, this figure illustrates the volatility of rainfall in the municipality; the lowest cumulated rainfall in period 1967-2012 was registered in 1982 and the highest cumulated rainfall was registered two years later. 
Missing climate data, which accounts for $6.6 \%$ of the available data, was filled using contemporary information from three weather stations that are closest to Anzaldo at similar distance above sea level. These weather stations are located in the municipalities of Sacabamba, Arani and Tarata, which are municipalities belonging to the high valley of Cochabamba and provide climate information that is closely related to that of the station of interest, as depicted by their respective correlation coefficients: $0.7,0.79$ and 0.8 .

The three techniques for filling missing data have been performed and their respective MSEs were calculated. The Simple Average, The Weighted Linear Combination and the Multiple Regression yielded, respectively, MSE of 27.3, 24.4 and 22.2. Hence Multiple Regression proves best for filling missing data in the climate conditions time series of interest.

\section{Climate Risk Indexing}

As it has been stressed in previously, an adequate management of basis risk requires a precise definition of the coverage limits of the insurance scheme. We want to make the case that most of this risk needs to be managed before climate indexing and that this task is not solely linked to intense use of financial techniques.

The identification of the area that is covered by the weather station is an element of paramount importance, for climate conditions are virtually unknown outside of this area. The weather station in Anzaldo has a $250 \mathrm{Km}$. radius range of coverage, and its position allows for precise knowledge of climate conditions in $40 \%$ of the municipality (see Fig. 4).

Furthermore, inside the area covered by the weather station, different physical and chemical characteristics of the land might define different development patterns for the same crop, holding constant climate conditions. Building from information from Bolivian 
State project GeoBolivia ${ }^{7}$, the surface in the municipality can be divided in two types according to fertility characteristics of the soil: the southern area (light green in Fig. 4) has more fertile soils than the northern area (light mauve in Fig. 4).

Once the range of coverage and characteristics of the soil have been identified, different culture techniques and habits are also a potential source of basis risk. In order to approximate these important aspects of agriculture in the municipality, the surface can be divided in two according the major use of the land: the north-eastern area (dark green in Fig. 4) represents land used permanently for agriculture, whereas the south-western area (dark yellow in Fig. 4) represents land of mixed use between agricultural activities and other activities such as livestock.

7 This project is managed by the Bolivian State Vice-presidency Office and offers publicly available geographic information. 


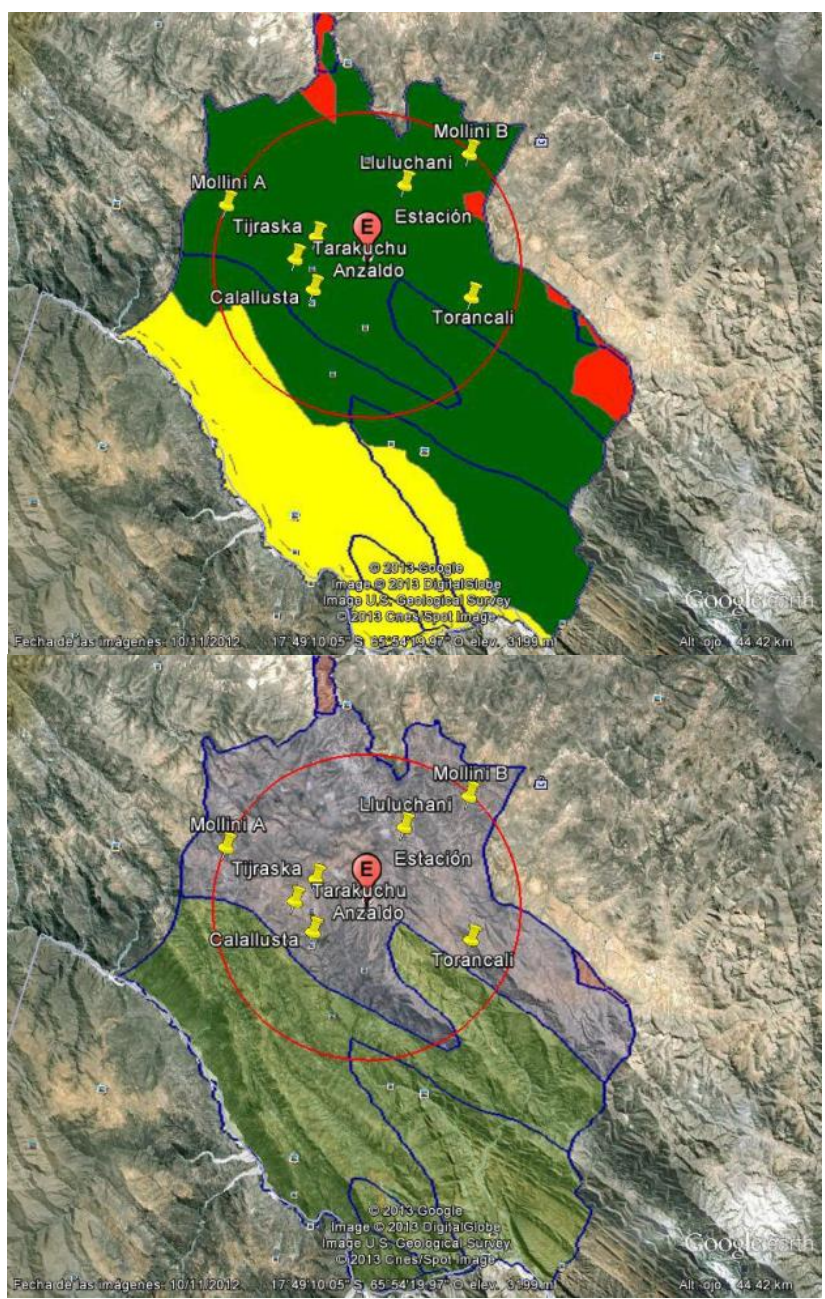

Fig. 4 Soil

Division in Anzaldo and Range of Coverage of the Weather Station

As depicted in Fig. 4, the most part of the range covered by the weather station corresponds to land used for permanent agriculture activities in the northern area of the municipality. Since there are no complementary weather stations covering the rest of the surface, time series of climate information for this area does not exist, thus the conception of a climate index-based insurance scheme for this surface 
may entail a considerable cost in terms of basis risk. This is why, in order to minimize as much as possible the basis risk through homogeneity criteria, the insurance schemes were developed only for crop fields lying on the range covered by the weather station within the surface that is permanently used for agricultural activities.

Time series of crop yields for potato and wheat of intermediate cycle (13 decadals each) are inexistent in public records. Thus they were estimated using FAO's AquaCrop, because all the climate parameters needed for its calibration are available from information provided by the weather station in Anzaldo. The size of the estimated time series corresponds to the span of time of the available climate data, i.e. 1967-2012 or 45 periods of time.

The models for indexing climate risks were estimated in different forms for each of the crops of interest. The general econometric framework respects the form that was proposed, but its elements take different configurations for each plausible indexing model. A clear description of these models is presented see Table 1, that builds on the matrix form of the generic indexing model:

$y_{t}=\beta_{0}+\sum_{d=1}^{D} C D R_{t, d} \cdot \beta_{d}+\boldsymbol{Z}_{t} \boldsymbol{\gamma}+\varepsilon_{t}=\beta_{0}+\boldsymbol{C D} \boldsymbol{R}_{\boldsymbol{t}} \cdot \boldsymbol{\beta}+\boldsymbol{Z}_{\boldsymbol{t}} \boldsymbol{\gamma}+\varepsilon_{t}$

Table 1. Comparison of Estimated Yield and Public Information

\begin{tabular}{|c|c|c|}
\hline \multicolumn{2}{|c|}{ Crop ModelCDR M $_{\mathrm{t}}$} & \multirow{2}{*}{$\begin{array}{l}Z_{\boldsymbol{t}} \text { (control variables) } \\
\text { Sized }(1 \times 4) \text { and identical } \\
\text { for all models. This vector } \\
\text { includes a dummy variable } \\
\text { for period } 1991-1992 \\
\text { capturing the effects of a }\end{array}$} \\
\hline Wheat 1 & $\begin{array}{l}\text { Sized }(1 \times 13) \text {, including } \\
\text { the cumulated disposable } \\
\text { rainwater in each of the } 13 \\
\text { decadals of the wheat } \\
\text { agricultural cycle. }\end{array}$ & \\
\hline 2 & $\begin{array}{l}\text { Sized }(1 \times 1) \text {, including } \\
\text { the cumulated disposable }\end{array}$ & $\begin{array}{l}\text { severe manifestation of El } \\
\text { Niño phenomenon, a }\end{array}$ \\
\hline
\end{tabular}


rainwater between decadals dummy variable for period 3 and 12, i.e. days 21-120. 2010-2011 capturing the Potato1 Sized $(1 \times 13)$, including negative effects of a severe the cumulated disposable manifestation of La Niña in rainwater in each of the 13 decadals of the wheat the continent, as well as agricultural cycle. linear trend $(t)$ and a quadratic trend: $\left(t^{2}\right)$

$2 \quad$ Sized $(1 \times 2)$, including the cumulated disposable rainwater between i) days 11-36 and ii) days 37-130

The climate index for wheat crops has been created on the grounds of statistical criteria from two plausible indexing models. Model 1 (see Table 2) was estimated first, as a general one, allowing for different effects on yield coming from cumulated disposable rainfall in each decadal. Differences in the cumulated disposable rainwater in the first and the last decadals do not cause significant effects on the yield as opposed to the rest of the development cycle, which is entirely statistically significant, thus defining what one might call a critical period for wheat crops.

Successive Wald tests reject the existence of a hierarchy between the effects of the different decadals that are part of the above mentioned critical period. In other terms, from a strictly statistical perspective, there is evidence for the fact that water stress for wheat crops in this region has a homogeneous effect on yield if it occurs between days 21 and 120 of its development cycle. These facts allow us to propose Model 2 in Table 3 as a plausible indexing model, which regroups the cumulated disposable rainwater in the critical period in one single variable. 
Table 2. Estimation Results of Climate Risk Indexing Models for Wheat in Anzaldo

\begin{tabular}{|c|c|c|}
\hline & $\begin{array}{l}\text { Model } \\
1 \\
\end{array}$ & $\begin{array}{l}\text { Model } \\
2 \\
\end{array}$ \\
\hline Variable & Coefficient & Coefficient \\
\hline Constant & $-0.782 * * *$ & $-0.761 * * *$ \\
\hline CDR decadal 1 & 0.0003 & \\
\hline CDR decadal 2 & 0.002 & \\
\hline CDR decadal 3 & $0.004 * * *$ & \\
\hline CDR decadal 4 & $0.003 * *$ & \\
\hline CDR decadal 5 & $0.004 * * *$ & \\
\hline CDR decadal 6 & $0.004 * *$ & \\
\hline CDR decadal 7 & $0.003 * *$ & \\
\hline CDR decadal 8 & $0.004 * * *$ & \\
\hline CDR decadal 9 & $0.003 * *$ & \\
\hline CDR decadal 10 & $0.004 * *$ & \\
\hline CDR decadal 11 & $0.005 * * *$ & \\
\hline CDR decadal 12 & $0.006 * * *$ & \\
\hline \multirow[t]{2}{*}{ CDR decadal 13} & - & \\
\hline & 0.0004 & \\
\hline CDR days 21-120 & & $0.004 * * *$ \\
\hline D1991 & $-0.461 * *$ & $-0.499 * * *$ \\
\hline D2001 & $0.528 * * *$ & $0.497 * * *$ \\
\hline D2010 & $-0.413 * *$ & $-0.422 * * *$ \\
\hline Linear trend & $0.026 * *$ & $0.024 * * *$ \\
\hline \multirow[t]{2}{*}{ Quadratic trend } & $-\quad *$ & $-\quad * * *$ \\
\hline & 0.0003 & 0.0003 \\
\hline$R 2$ & 0.87 & 0.83 \\
\hline
\end{tabular}


Adjusted $R_{2} \quad 0.78 \quad 0.81$

Observations $\quad 45 \quad 45$

* Significance at $10 \%$; ** Significance at 5\%; $* * *$ Significance at 1\%; CDR Cumulated disposable rainwater; D1990 dummy=1 if agricultural period is 1990-1991; D2001 dummy=1 if agricultural period is 2001-2002; D2010 dummy=1 if agricultural period is 2010-2011

A comparison between adjusted $\mathrm{R}_{2}$ values corresponding to both plausible indexing models, leads to choose Model 2 and its corresponding critical period as an appropriate climate index for wheat crops in this region. This model accounts for $83 \%$ of the yield variance (see Fig. 5) and allows deducing that, at 95\% confidence, a reduction between 3.4 and $4.8 \mathrm{Kg} / \mathrm{ha}$ in the yield is caused by a reduction in $1 \mathrm{~mm}$. of the cumulated disposable rainwater in the critical period.

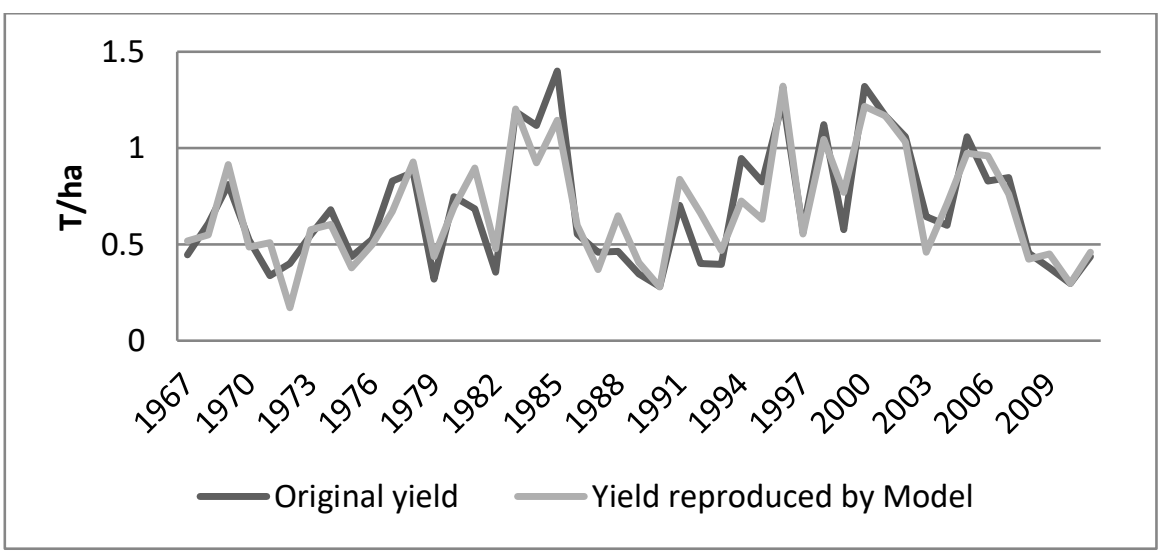

Fig. 5 Original Yield and Yield Reproduced by Indexing Model for Wheat in Anzaldo

Climate risk for potato crops in the region was indexed following a strategy similar to the one performed for treating risk in what crops. A generic model, Model 1 in Table 3, was estimated allowing for 
different effects on yield caused by cumulated disposable rainwater in each decadal. However, the results lead to a different interpretation of this relation. Changes in the cumulated disposable rainwater cannot be regrouped in a homogenous period of time within the agricultural cycle on the grounds of a pure statistical analysis, as was the case of wheat crops. As shown in Table 4, Model 1 detects statistically significant effects of rainfall conditions in decadals 3, 6-9, 11 and 12 .

This is a case that shows that statistical-based reasoning can be fruitfully supplemented with agricultural criteria for risk indexing. The phenology for potato can be divided in two stages: the first is called the vegetative stage and occurs between days 11 and 36 after sowing; the second is called reproductive stage and occurs between days 37 and 130 after sowing. Model 2 in Table 4 was estimated including the cumulated disposable rainfall in these phenological stages.

The adjusted $\mathrm{R}_{2}$ of Model 2 leads to choose it as a better indexing model. According to Model 2, which accounts for $72 \%$ of yield variation (see Fig. 6), changes in cumulated disposable rainfall have similar quantitative effects on potato yield whether they occur in the vegetative or the reproductive stages. A $1 \mathrm{~mm}$. reduction of cumulated disposable rainwater in one of the phenological stages causes a reduction of yield between 31.2 and $29.7 \mathrm{Kgs} / \mathrm{ha}$, with $95 \%$ confidence.

Table 3. Estimation Results of Climate Risk Indexing Models for Potato in Anzaldo

\begin{tabular}{lll}
\hline & Model & Model \\
& 1 & 2 \\
\hline Variable & Coefficient & Coefficient \\
\hline Constant & $-5.446 * *$ & -1.750 \\
CDR decadal 1 & 0.062 & \\
\hline
\end{tabular}




\begin{tabular}{|c|c|c|}
\hline CDR decadal 2 & 0.023 & \\
\hline CDR decadal 3 & $0.034 *$ & \\
\hline CDR decadal 4 & 0.016 & \\
\hline CDR decadal 5 & 0.008 & \\
\hline CDR decadal 6 & $0.039 *$ & \\
\hline CDR decadal 7 & $0.055 * * *$ & \\
\hline CDR decadal 8 & $0.034 *$ & \\
\hline CDR decadal 9 & $0.048 * * *$ & \\
\hline CDR decadal 10 & 0.020 & \\
\hline CDR decadal 11 & $0.035 * *$ & \\
\hline CDR decadal 12 & $0.046 * *$ & \\
\hline CDR decadal 13 & 0.029 & \\
\hline CDR days 11-36 & & $0.029 * * *$ \\
\hline CDR days 37-130 & & $0.031 * * *$ \\
\hline$D 1991$ & $-4.574 * *$ & $-4.519 * *$ \\
\hline D2010 & $-4.675 * *$ & $-5.483 * * *$ \\
\hline Linear trend & 0.102 & 0.018 \\
\hline Quadratic trend & $\begin{array}{l}- \\
0.0008\end{array}$ & 0.0008 \\
\hline$R_{2}$ & 0.80 & 0.72 \\
\hline Adjusted $R_{2}$ & 0.61 & 0.68 \\
\hline Observations & 45 & 45 \\
\hline
\end{tabular}

* Significance at 10\%; ** Significance at 5\%; *** Significance at 1\%; CDR Cumulated disposable rainwater; D1996 dummy=1 if agricultural period is 1996-1997; D2010 dummy=1 if agricultural period is $2010-2011$

It is important to notice that the similarity of effects caused by rainwater deficit in both phenological stages does not imply that there 
are similar risks in both stages because rainwater deficit has different probability of occurrence. In effect, in period 1967-2011, the standard deviation of cumulated disposable rainfall in the reproductive stage is $57 \mathrm{~mm}$., whereas that of the vegetative stage is $42 \mathrm{~mm}$. Furthermore, cumulated disposable rainwater in the reproductive stage presents a steeper decreasing trend $(1.16 \mathrm{~mm}$. year) than that of the vegetative stage $(0.97 \mathrm{~mm}$./year). These facts constitute importance evidence for identifying the reproductive stage as a more risky period that the vegetative stage, thus advocating for the first as a suitable climate index for potato crops in the region.

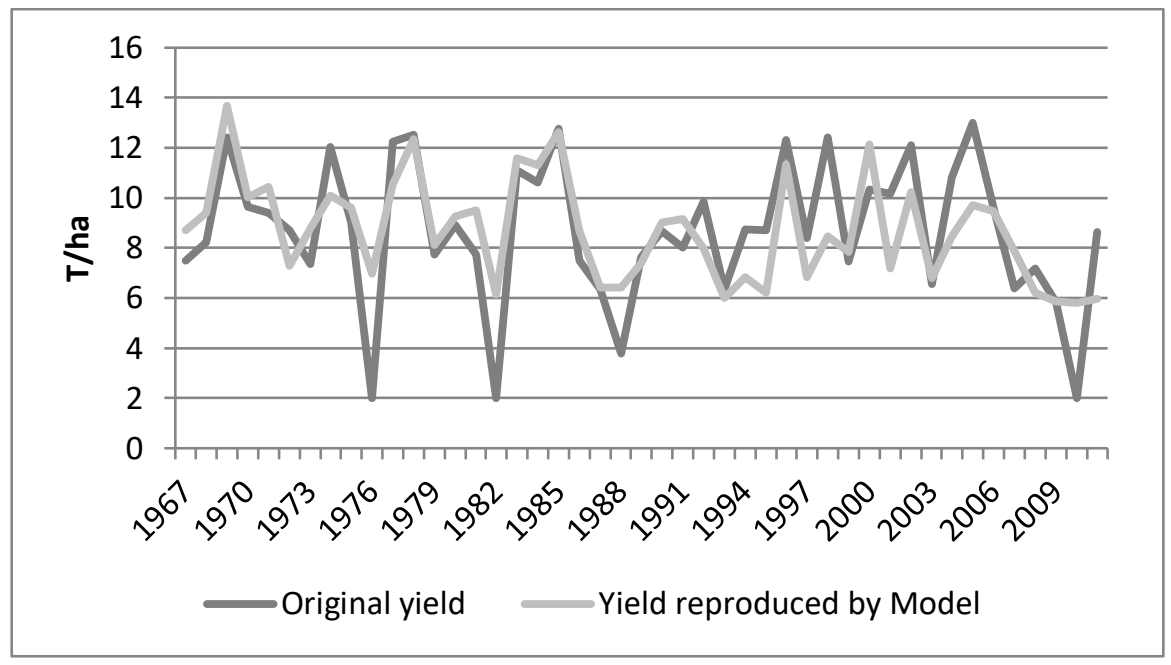

Fig. 6 Original Yield and Yield Reproduced by Indexing Model for Potato in Anzaldo

\section{Climate Risk Quantification}

Once the climate indices have been defined for each crop, climate risk quantification is relatively straightforward. Kolmogorov-Smirnov tests allow to determine parametric forms of distributions underlying 
climate indices time series, thus quantifying climate risks in the region. The results of these tests are presented in Table 4.

Table 4. Characteristics of Proposed Distributions for the Climate Indices

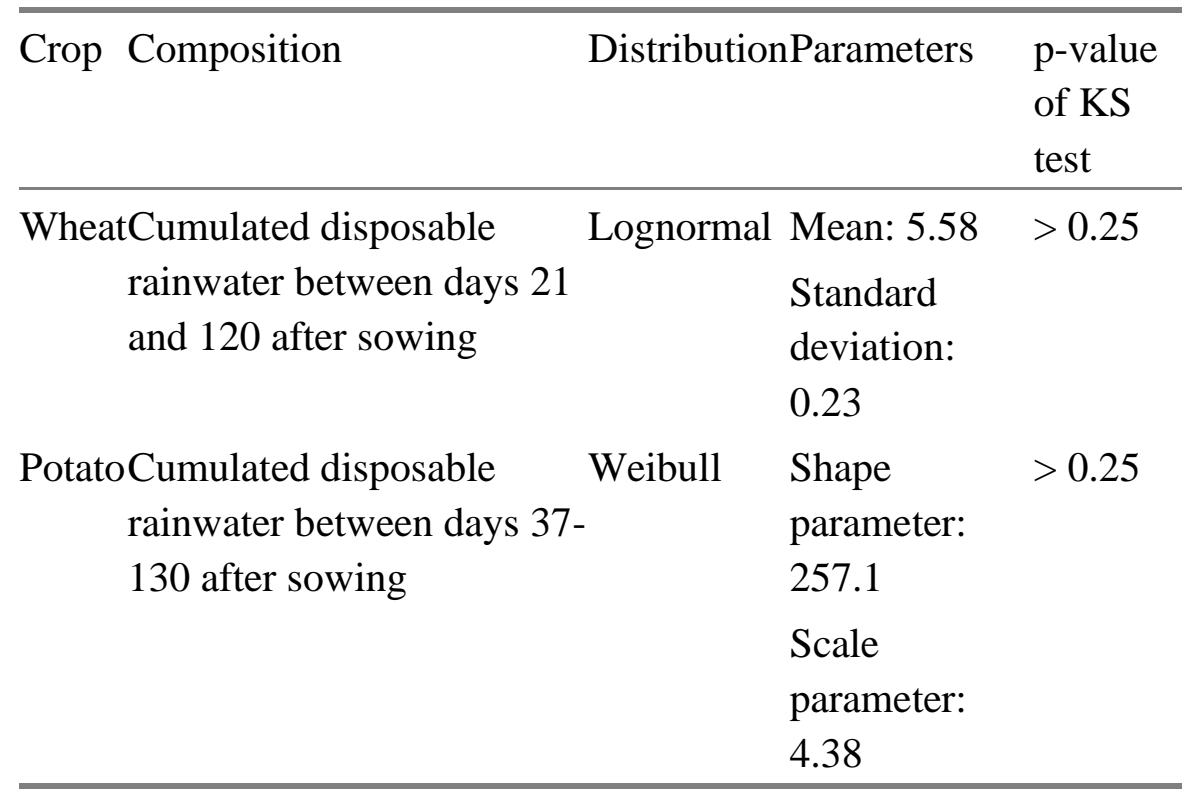

\section{Proposed Insurance Schemes}

The proposed methodology was used for the construction of two types of insurance schemes: fixed reimbursement schemes and variable reimbursement schemes. Climate index-based insurance schemes normally adopt the latter configuration that determines reimbursement though an assessment of the climate-induced damage to the crop [Hatch et al., 2012; Osgood et al., 2007]. This means that reimbursement rises as climate conditions worsen. Although fixed reimbursement schemes are less common to climate index-based insurance, it is important to take them into account in order to 
compare these insurance schemes to the current schemes of UAIP that consider only fixed reimbursement.

Thus the expected reimbursement for the producers can be calculated. This value depicts the core of the actual market prices of the insurance policies.

\section{Fixed Reimbursement Insurance Schemes}

According to specific studies in the rural region that we study ${ }^{8}$, the average production costs of wheat and the region is $198.70 \mathrm{USD} / \mathrm{T}$ and those of potato rise to $133.60 \mathrm{USD} / \mathrm{T}$. These costs correspond to the median yields of wheat and potato simulated by AquaCrop, which are, respectively 0.8 and $7.9 \mathrm{~T} / \mathrm{ha}$, and they may considered to be plausible representative values of a rational yield expectation, or 'regular' yields, from the perspective of the producers.

The trigger for these insurance schemes is associated to $51 \%$ of the median yield for wheat crops, depicting $0.41 \mathrm{~T} / \mathrm{ha}$ and to $44 \%$ of the median yield of potato crops, depicting $3.5 \mathrm{~T} / \mathrm{ha}$. These yields correspond to those that generate a full reimbursement for producers in the current UAIP framework for the 2013-2014 agricultural cycle. All the characteristics of the proposed fixed reimbursement schemes are presented in Table 5.

Instead of defining a single value of reimbursement for all crops, as is currently the case in UAIP scheme, this value may be associated to the production costs of each crop. Thus the insurance policies are labeled at nominal values of 101.40 USD/ha for wheat producers and 467.70 USD/ha for potato producers. These values represent the maximum reimbursement for each crop.

\footnotetext{
${ }^{8}$ These studies were specifically carried on for the study of wheat and potato in Anzaldo by Proinpa Foundation in 2010.
} 
According to the climate risk indexing that we performed, there is $90 \%$ confidence $^{9}$ that the trigger-related yields will not be attained by producers if the following conditions are true:

- the climate index for wheat (i.e. cumulated disposable rainwater between days 21 and 120 after sowing of wheat crops) is lower than $206 \mathrm{~mm}$. This value represents the activation trigger of the climateindex based insurance schemes for wheat crops and it has a probability of occurrence of $13 \%$.

- the climate index for potato (i.e. cumulated disposable rainwater between days 37 and 130 after sowing, which corresponds for the reproductive stage) is lower than $158 \mathrm{~mm}^{10}$. As in the previous case, this value represents the activation trigger of the climateindex based insurance schemes for potato yields, and it has a probability of occurrence of $11 \%$.

Thus the expected reimbursement is $13.20 \mathrm{USD} /$ ha for wheat producers and $52.50 \mathrm{USD} /$ ha for potato producers. These values represent the core of insurance policy prices and correspond, respectively, to $13 \%$ and $11 \%$ of the reimbursement received by the producers if the insurance triggers.

Table 5. Parameters of the Fixed Reimbursement Insurance Schemes

\begin{tabular}{lll}
\hline Parameter & Wheat & Potato \\
\hline Regular yield (T/ha) & 0.80 & 7.90 \\
Coverage rate of regular yield & $51 \%$ & $44 \%$ \\
Insured yield (T/ha) & 0.41 & 3.50 \\
\hline
\end{tabular}

\footnotetext{
${ }^{9}$ This means that there is only $10 \%$ of probability that producer will not receive the reimbursement, having had yields lower than those associated to the trigger. In other terms, the policies that we propose imply a $10 \%$ basis risk for the producers.

${ }^{10}$ This value was calculated for cumulated disposable rainwater of $35 \mathrm{~mm}$. in the vegetative stage (1-36 days after sowing), which corresponds to the historical mean value of rainwater in this period (77 mm.) minus one standard deviation $(42 \mathrm{~mm}$.), depicting a pessimistic scenario for the producers.
} 


\begin{tabular}{lll}
$\begin{array}{l}\text { Nominal value (or value of the insured yield, } \\
\text { USD/ha) }\end{array}$ & 101.40 & 467.70 \\
Climate index (period after sowing, in days) & $\begin{array}{l}21 \text { to } \\
120\end{array}$ & $\begin{array}{l}37 \text { to } \\
130\end{array}$ \\
& 206 & 158 \\
Activation trigger (mm.) & $13 \%$ & $11 \%$ \\
Probability of occurrence & 13.20 & 52.50 \\
Expected reimbursement to producers (USD/ha) & \\
Ratio Expected reimbursement / Nominal value & 0.13 & 0.11 \\
\hline
\end{tabular}

\section{Variable Reimbursement Schemes}

These schemes have similar parameters to the previous ones, yet they hold some important different characteristics (Table 6). As opposed to the previous schemes, variable reimbursement implies two different triggers: an activation trigger that ignites reimbursement and an exit trigger that implies a full reimbursement to the producer, i.e. a payment equivalent to the nominal value of the insurance. In these schemes, reimbursement increases at a pace given by the reimbursement rate.

The activation triggers are defined similarly to the previous schemes that were presented. For the definition of the exit triggers, one can consider that full reimbursement of production costs is pertinent when, after harvest, the obtained yield does not even allow for coverage of harvesting costs. In this case, it would be preferable to leave the obtained yield on the field and the situation could be defined as catastrophic for the producer. The harvesting costs in the region are estimated at $71.50 \mathrm{USD} / \mathrm{ha}$ of wheat and $138.70 \mathrm{USD} / \mathrm{ha}$ for potato. Following strategic planning of public policies in Anzaldo the market prices of wheat and potato are, respectively, 303.- and 250.- USD/T. Thus the catastrophic situation arises when wheat yield drops to $0.24 \mathrm{~T} / \mathrm{ha}$ and potato yield drops to $0.6 \mathrm{~T} / \mathrm{ha}$. According to 
the climate risk indexing that we performed, there is $90 \%$ confidence that this catastrophic yields are attained when climate indices for wheat and potato take values of $159 \mathrm{~mm}$. and $7.1 \mathrm{~mm}$., respectively, which occur with probabilities of $1.1 \%$ and $~ 0.1 \%$.

Table 6. Parameters of the Variable Reimbursement Insurance Schemes

\begin{tabular}{lll}
\hline Parameter & Wheat & Potato \\
\hline Regular yield (T/ha) & 0.80 & 7.90 \\
Coverage rate of regular yield & $51 \%$ & $44 \%$ \\
Insured yield (T/ha) & 0.41 & 3.50 \\
Nominal value (or value of the insured yield, & 101.40 & 467.70 \\
USD/ha) & & \\
Climate index (period after sowing, in days) & 21 to & 37 to \\
& 120 & 130 \\
Activation trigger (mm.) & 206 & 158 \\
Probability of occurrence of activation trigger & $13 \%$ & $11 \%$ \\
Exit trigger (mm.) & 159 & 7.1 \\
Probability of occurrence of exit trigger & $1.1 \%$ & $\sim 0.1 \%$ \\
Reimbursement rate (USD/mm.) & 2.15 & 3.10 \\
Expected reimbursement to producers (USD/ha) & 5.60 & $10 .-$ \\
Ratio expected reimbursement / nominal value & 0.06 & 0.02 \\
\hline
\end{tabular}

Brief Summary and Discussion of Proposed Insurance Schemes

A comparison between fixed and variable reimbursement schemes sheds interesting light on superior adequacy of the latter as a climate risk management technique; this affirmation is supported by data presented in Table 7. 
When reimbursement is variable, its expected value reduces considerably for both crops: nearly $70 \%$ in the case of wheat (from 13.20 USD/ha to $4.10 \mathrm{USD} / \mathrm{ha}$ ) and nearly $80 \%$ (from $52.50 \mathrm{USD} / \mathrm{ha}$ to 10.- USD/ha). This is due to the distribution of reimbursements in a range of values instead of only one fixed value. Through variable reimbursement schemes, the probability of high payments to the producers is reduced and conditioned to climate conditions that cause severe damage, which occur less often. This is depicted in the probabilities of full payment to the producers in the case of variable reimbursement, which drop from $13 \%$ to $1.1 \%$ for wheat crops and from $11 \%$ to practically null probability for potato crops.

Thus variable reimbursement schemes allow for a considerable reduction of the core of the insurance policy price, because it allows the ratio expected reimbursement / nominal value of the insurance to drop from $13 \%$ to $4 \%$ for wheat crops and from $11 \%$ to $2 \%$ for potato crops. These schemes represent lower expected costs for insurers, thus variable reimbursing has a better potential of motivating the expansion of private insurers in crop insuring services in the country, as opposed to fixed reimbursement schemes.

At this stage, it is useful to compare the fixed reimbursement schemes that have been constructed using the proposed methodology, to the actual configuration of UAIP. The latter public insurance offers a fixed reimbursement for all types of considered crops of 144 USD/ha within a fully subsidized mechanism. According to these policies, this value may result attractive for wheat producers in Anzaldo, but not for potato producers. The value of expected production of the first is considerably lower than that of the latter, which is more than three times the reimbursement offered by the government.

The amount offered by UAIP, though, does manage to compensate for harvesting costs related to both crops in the region, thus this public insurance would correspond to a catastrophic one in the logic that was described earlier. 
Table 7. Summary of Policy Characteristics

\begin{tabular}{|c|c|c|c|c|}
\hline & Wheat & & Potato & \\
\hline & $\begin{array}{l}\text { Fixed } \\
\text { reimburseme }\end{array}$ & $\begin{array}{l}\text { Variable } \\
\text { reimburseme }\end{array}$ & $\begin{array}{l}\text { Fixed } \\
\text { reimburseme }\end{array}$ & $\begin{array}{l}\text { Variable } \\
\text { reimburseme }\end{array}$ \\
\hline & nt & $\mathrm{nt}$ & nt & $\mathrm{nt}$ \\
\hline $\begin{array}{l}\text { Nominal } \\
\text { Value } \\
\text { (USD/ha) (a) }\end{array}$ & 101.40 & 101.40 & 467.70 & 467.70 \\
\hline $\begin{array}{l}\text { Expected } \\
\text { Reimburseme } \\
\text { nt (USD/ha) } \\
\text { (b) }\end{array}$ & 13.20 & 4.10 & 52.50 & 10.- \\
\hline Ratio (b) / (a) & 0.13 & 0.04 & 0.11 & 0.02 \\
\hline $\begin{array}{l}\text { Probability of } \\
\text { full } \\
\text { reimbursemer } \\
t\end{array}$ & $13 \%$ & $1.1 \%$ & $11 \%$ & $\sim 0.1 \%$ \\
\hline $\begin{array}{l}\text { Harvesting } \\
\text { Costs } \\
\text { (USD/ha) }\end{array}$ & 71.50 & 71.50 & 138.70 & 138.70 \\
\hline
\end{tabular}

\section{Concluding Remarks}

- As has been the case in many developing countries, climate-index based crop insurance in Bolivia is currently being promoted by public authorities with limited participation of the private financial sector. Crop insurance, in general, has been identified by the State as a priority for food safety and sovereignty as well as social 
wellbeing in the country, which has reflected on the creation and impulse to the National Institution for Agricultural Insurance. This institution has managed to reach rural regions that have been historically deprived of financial services and present crop insurance to producers all around the country.

- However, since the only widely accepted crop insurance in the country, UAIP, is offered though a fully subsidized program, one cannot say that there is a true market for crop insurance in the county yet. Progressively increasing participation of the private financial sector requires the creation of market-driven process of policy pricing, through the development and increase of demand for this services, alongside willingness-to-pay from producers and the capacities for suppliers to sustainably provide the service.

- Concentrating on the suppliers' capacities for crop insuring in the country, it has been shown that reliable sources of quality information for the construction of climate index-based insurance schemes are publically available in Bolivia. Furthermore, sound techniques for the treatment of this information have been successfully applied. Thus, from a technical point of view, all the characteristics of these insurance schemes that have been orderly presented can be effectively assessed and undertaken by public and private suppliers in the country. The construction of the pilot insurance schemes presented in this chapter build from information that can be gathered in two large groups: i) climate data and ii) crop data.

- Referring to climate data collected by currently active weather stations in the country, it has been shown that they provides sufficient information for climate-risk indexing (i.e. rainwater and temperature) and that it allows to correctly use a widely known agro-biological system for crop yield assessment: FAO's Aquacrop.

○ There is, however, the opportunity to increase the density of official weather stations in the country, so 
that climate-risk indexing can be performed anywhere in the Bolivian territory. This task is important and particularly challenging for competent authorities because of the irregular geographical configuration of the country.

- Crop data availability has proven to be far more challenging for successful climate-risk indexing in Bolivia. The inexistence of yield time series with the adquate specific details to successfully manage basis risk poses considerable challenges for the development of climate index-based insurance schemes in the country. Ideally, the adequate management of basis risk requires specific time series for each crop variety and corresponding to the specific region of production. Without this level of disaggregation, climate-risk indexing is hindered by increased basis risk induced by extrapolations. We have shown that through the aforementioned Aquacrop, synthetic yields for specific crops in specific regions can be successfully constructed, but since it is still a data simulation procedure, although basis risk is more controlled, it is still intrinsically present.

- Crop yield data needs to be supplemented with other and region crop specific information, namely total production costs, harvesting costs and market prices. This information allows the quantification of climate risk in monetary terms, allowing for the construction of insurance policies and financial risk assessment for the insurers. The availability of this information is also particularly challenging in the Bolivian case, because of the lack of official current data. Each municipality has a publicly available Municipal Development Plan 
(MPD) and it may be the main source for the information that we describe here. This information, though, has to supplemented with data coming from experts in the region, such as NGO's technicians, provided they are recognized to offer information of quality and reliability comparable to that of public authorities.

- A crop insurance market in Bolivia can be developed on the grounds of variable reimbursement schemes, as it has been proven that they allow to lower expected reimbursement from the insurers' perspective, as opposed to fixed reimbursement schemes similar to the catastrophic insurance currently provided by the Bolivian government. The reduction in the expected payment to producers through variable reimbursement schemes is fairly intuitive and it has been shown that is drops between $70 \%$ and $80 \%$ for the crops that we have analysed, while allowing managing the same climate risk as fixed reimbursement schemes. Thus variable reimbursement schemes may result in more attractive policy contracts for insured producers, potentially igniting market-driven demand for this service.

- Although we have established the core of policy prices for the analysed crops in Anzaldo, i.e. the expected reimbursement, actual prices will be determined supplementing this information with administrative cost analyses and risk prime definition. Identification of policy prices is beyond the scope of this chapter because it is heavily influenced by suppliers practice and strategic risk management. Different options arise, such as own risk management or several reinsuring possibilities. However, variable reimbursement schemes are a better option for risk management that allow administrative cost management with less probability of hindering the expansion of the demand for this service.

- This chapter started arguing for the superiority of climate-index based schemes over traditional insurance schemes for fostering 
sustainable development of a crop insurance market in the country. Furthermore, it has been mentioned that variable reimbursement insurance is a more efficient risk management scheme than fixed reimbursement insurance. Although a case study like the one that is presented here cannot be source of demonstration for these statements, it does bring about a useful illustration. In the last agricultural period (2012-2013), 8'470 ha of the 91'226 ha that are insured for all crops by UAIP suffered confirmed damage caused by negative climate conditions, depicting an accident rate of $9.3 \%$. Taking into account the fixed reimbursement of $144 \mathrm{USD} / \mathrm{ha}$, last year's average ex-post expectation of reimbursement is 13.4 USD/ha, implying a 0.09 average ratio expected reimbursement / insured value. This ratio is lower than values 0.13 and 0.11 that we have calculated for fixed reimbursement insurance for wheat and potato in Anzaldo, respectively, but it is higher than values 0.04 and 0.02 obtained through variable reimbursement schemes, for the same crops and the same climate risks. Thus the analysis that is provided here emphasize the attractiveness of variable reimbursement climate index-based as one suitable mechanism to ignite and develop a true market for this service in Bolivia, helpful for sustainable social and economic development.

\section{References}

Barnett B, Mahul O (2007). Weather index insurance for agriculture and rural areas in lower income countries. American Journal of Agricultural Economics 89: 1241-1247

Barnett B (2014). Crop insurance: successes and challenges. Agricultural Finance Review 34(3): 401-424

Collier B, Skees JR, Barnett BJ (2009). Weather index insurance and climate change: opportunities and challenges in lower income 
countries. Geneva Papers On Risk and Insurance - Issues and Practice 34: 401-424. doi: 10.1057/gpp.2009.11

Deng X, Barnett BJ, Hoogenboom G, Yu Y, Garcia A (2008). Alternative crop insurance indexes. Journal of Agricultural and Applied Economics 40: 223-237

Dercon S (2004) Growth and shocks, evidence for rural Ethiopia. Journal of Development Economics 74: 309-329.

Dinku T, Giannini A, Hansen J, Holthaus E, Ines A, Kaheil Y, Karnauskas K, Lyon B, Madajewicz M, Mclaurin M, Mullally C, Norton M, Osgood D, Peterson N, Robertson A, Shirley K, Small C, Vicarelli M (2009) Designing index-based insurance for farmers in Adiha, Ethiopia. IRI Technical Report 09-04. International Research Institute for Climate and Society, Columbia University.

Fenner M (1996) The phenology of growth and reproduction plants. Perspectives in Plant Ecology, Evolution and Systematics 1(1): 7891. doi: 10.1078/1433-8319-00053

Flores-Gallardo H, Ojeda-Bustamante W, Flores-Magdaleno H, Sifuentes-Ibarra E, Mejía-Saenz E (2013). Simulation of corn (Zea Mays) yield in northern Sinaloa using the Aquacrop model. Agrociencia 47(4): 347-359

Giné X. (2009) Experience with weather index-based insurance in India and Malawi. In: Vargas R, Torero M (eds.) Innovations in Insuring the Poor. International Food Policy Research Institute, Washington,USA.

Hatch D, Nuñez M, Vila F, Stephenson K (2012) Los seguros agropecuarios en las Américas: un instrumento para la gestión del riesgo. Instituto Interamericano de Cooperación para la Agricultura, IICA, San José, C.R.

Hazell P, Pomareda C, Valdés A (1992) The appropriate role of agricultural insurance in lower income countries. Journal of International Development 4(6): 567-581.

Hellmuth, ME, Osgood DE, Hess U, Moorhead A, Bhojwani H. (eds.) (2009). Index insurance and climate risk: prospects for 
development and disaster management. Climate and Society No. 2 International Research Institute for Climate and Society, Columbia University, New York, USA.

Hoogenboom J, Jones C, Porter P, Wilkens K, Boote W, Batchelor L, Hunt L, Tsuji G (2003) Decision support system for Agrotechnology Transfer Version 4.0, Volume 1: Overview. University of Hawaii, Honolulu.

Jones JW, Hoogenboom G, Porter CH, Boote KG, Batchelor WD, Hunt LA, Wilkens PW, Singh U, Gijsman AJ, Ritchie JT (2003). The DSSAT cropping system model. European Journal of Agronomy 18: 235-265.

Mertz O, Halsnaes K, Olesen J. (2009) Adaptation to climate change in developing countries. Environmental Management 43:743-752. doi: 10.1007/s00267-008-9259-3

Osgood D. McLaurin M, Carriquiry M, Mishra A, Fiondella F, Hansen J, Peterson N, Ward N (2007) Designing index-based insurance for farmers in Malawi, Tanzania and Kenya. IRI Technical Report 07-02. International Research Institute for Climate and Society, Columbia University.

Pabón JD, Dorado J (2008) Intraseasonal variability of rainfall over northern South America and Caribbean region. Earth Science Research Journal 12(2): 194-212.

Raes D, Steduto P, Hsiao T, Fereres E, (2009) AquaCrop, the FAO crop model to simulate yield response to water. Agronomy Journal 101:438-447.

Schneider T (2001) Analysis of incomplete climate data: estimation of mean values and covariance matrices and imputation of missing values. Journal of Climate 14(5): 853-871.

Skees, JR (2008). Challenges for use of index-based weather insurance in lower income countries. Agricultural Finance Review 68: $197-217$ 
Turlach B (1993) Bandwith selection in kernel density estimation: a review. Discussion Paper 9307, Institute for Econometrics and Statistics, University of Berlin.

Varangis P, Skees J, Barnett B (2002). Weather indexes for developing countries. In Climate Risk and the Weather Market: Financial Risk Management with Weather Hedges. RS Dischel (ed.) London, Risk Books.

Weber S (2006). Distribution-invariant risk measures, information and dynamic consistency. Mathematical Finance 16(2): 419-441. doi: 10.1111/j.1467-9965.2006.00277 